\title{
Generation and Structure of Unique Boriranyl Radicals
}

\author{
John C. Walton, ${ }^{* \dagger}$ Timothy R. McFadden, ${ }^{\ddagger}$ and Dennis P. Curran ${ }^{*}$ \\ ${ }^{\dagger}$ EaStCHEM School of Chemistry, University of St. Andrews, St. Andrews, Fife, KY16 9ST, United Kingdom. \\ * Department of Chemistry, University of Pittsburgh, Pittsburgh, Pennsylvania 15260, United States.
}

\section{Supporting Information Placeholder}

\begin{abstract}
Three-member ring boracyclopropanes (boriranes) with $N$-heterocyclic carbene substituents were prepared by a recently discovered route. $\mathrm{H}$-atoms were selectively abstracted from the boron atoms by t-butoxyl radicals and this enabled boriranyl radicals to be detected and characterized by EPR spectroscopy for the first time. Their EPR parameters indicated they had planar $\pi$-character. From competition experiments the rate constant for $\mathrm{H}$-atom abstraction was determined and found to be about two orders of magnitude less than for NHC-boranes. The B-H BDE of an NHC-borirane was estimated to be about $95 \mathrm{kcal} \mathrm{mol}^{-1}$.
\end{abstract}

Borirane is the nuclear analog of cyclopropane in which a $\mathrm{BH}$ group replaces a $\mathrm{CH}_{2}$ group to give a "boracylopropane". Boriranes are rare but recently several preparative routes to Lewis base stabilized boriranes have been described. In particular, Braunschweig ${ }^{1}$ and $\mathrm{Wang}^{2}$ reported several stable $N$-heterocyclic carbene substituted boriranes prepared from alkenes. Furthermore, some of us discovered a direct synthetic route by means of double hydroboration of acetylenedicarboxylate esters with NHCboranes. ${ }^{3}$ The accessibility of these types of functionalized boriranes opens the door to generating and spectroscopically characterizing hitherto unknown three-member ring boriranyl radicals.

Figure 1 shows the parent structures of three-member ring radicals centered on carbon, nitrogen and boron. The cyclopropyl radical is the archetype, and Fessenden and Schuler's classic EPR study revealed that these are $\sigma$-radicals with bent tetrahedral centers. Cyclopropyl radicals differ from most other alkyl radicals, which have planar $\pi$-character. Subsequent research showed that their pyramidal structure engenders stereoisomers, ${ }^{\square}$ and that they are thermodynamically less stable than methyl radicals. ${ }^{\square}$ Almost the only other heteroatom-centered, three-member ring radicals to be characterized are $N$-centered aziridinyls. In conspicuous contrast, these were found to be planar $\pi$-character radicals resembling other sec-aminyl radicals.

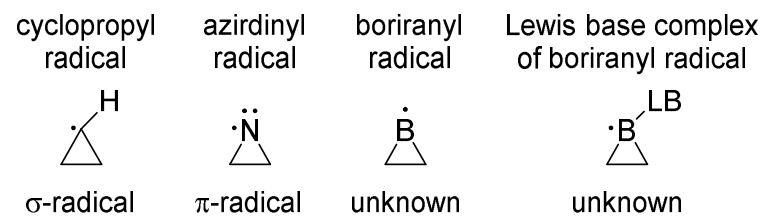

Figure 1. Structures of parent three-member ring radicals
Boron is the atom immediately to the left of carbon on the Periodic Table so its derived radicals are of fundamental interest. Boron has a valency and electronic structure that could support either a five-electron boriranyl radical or Lewis base complexed, seven-electron boriranyl radical. Despite their importance, boriranyl radicals are unknown; apart from a computational study. Here we report the first boriranyl radicals, generated as complexes with $N$-heterocyclic carbene Lewis bases. The radicals are characterized by EPR spectroscopy, calculations and competition kinetics.

The NHC-boriranes 3a,b were obtained as the major products from reactions of 1,3-diarylimidazol-2-ylidene boranes $\mathbf{1 a , b}$ with dimethyl but-2-ynedioate 2 (dimethyl acetylenedicarboxylate) in $\mathrm{MeCN}$ at $80{ }^{\circ} \mathrm{C}$ (Scheme 1) as described previously. ${ }^{3}$ Pure samples of 3a,b were isolated by automated flash chromatography, then recrystallized.

Previous research with $\mathrm{NHC}$-boranes $\left(\mathrm{NHC}^{\left.-\mathrm{BH}_{3}\right)}\right.$ has shown that $\mathrm{H}$-atoms are selectively abstracted from the $\mathrm{BH}_{3}$ groups by $t$ $\mathrm{BuO} \bullet$ radicals photochemically generated from di-t-butyl peroxide (DTBP). ${ }^{9}$ Hydrogen atoms are generally bonded very strongly to three-member rings ${ }^{6,1 \square}$ so it was not preordained that $t$-BuO• would selectively remove the (B)-H atoms from compounds 3 . Alternative sites for attack by $t$ - $\mathrm{BuO} \bullet$ include the benzylic hydrogen atoms of the $N$-aryl groups and the hydrogens of the methyl esters.

\section{Scheme 1. Preparation of Test NHC-Boriranes}

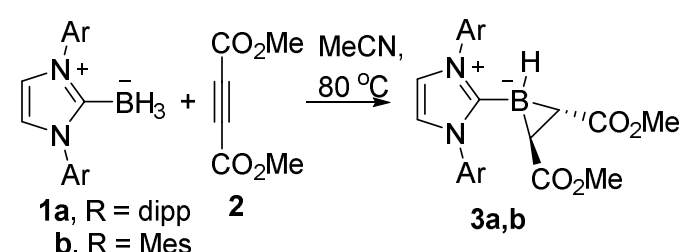

NHC-borirane 3a was sparingly soluble in $t$-butylbenzene. When solutions of 3a and DTBP in this solvent were UV irradiated in the resonant cavity of a $9 \mathrm{GHz}$ EPR spectrometer only the spectrum of the neophyl radical $\left(\mathrm{PhCMe}_{2} \mathrm{CH}_{2} \bullet\right.$ ) was observed at rt. ${ }^{11}$ Similarly, irradiation of suspensions of $\mathbf{3 a}$ in neat DTBP afforded only radicals derived from DTBP. These results gave an early indication that the $\mathrm{B}-\mathrm{H}$ bond of $\mathbf{3 a}$ was not markedly weaker than the primary $\mathrm{C}-\mathrm{H}$ bonds of $\mathrm{PhC}\left(\mathrm{CH}_{3}\right)_{3}$.

NHC-borirane 3a $(10 \mathrm{mg}, 0.018 \mathrm{mmol})$ and DTBP $(0.02 \mathrm{~mL})$ were then dispersed in benzene $(0.5 \mathrm{~mL})$ and the suspension was sonicated. A $0.2 \mathrm{~mL}$ sample was transferred to a quartz tube $(0.4$ $\mathrm{mm}$ dia.) and de-aerated by bubbling nitrogen for $c a .15 \mathrm{~min}$. This tube was irradiated in the resonant cavity of the EPR spec- 
trometer with unfiltered light from a 500 Watt high pressure $\mathrm{Hg}$ arc lamp. EPR spectra were scanned repeatedly at $280 \mathrm{~K}$; the sum of 150 such scans is displayed in Figure 2. A large broad central feature, most likely due to radicals trapped in the solid particles in the dispersion, was removed by digital filtration.

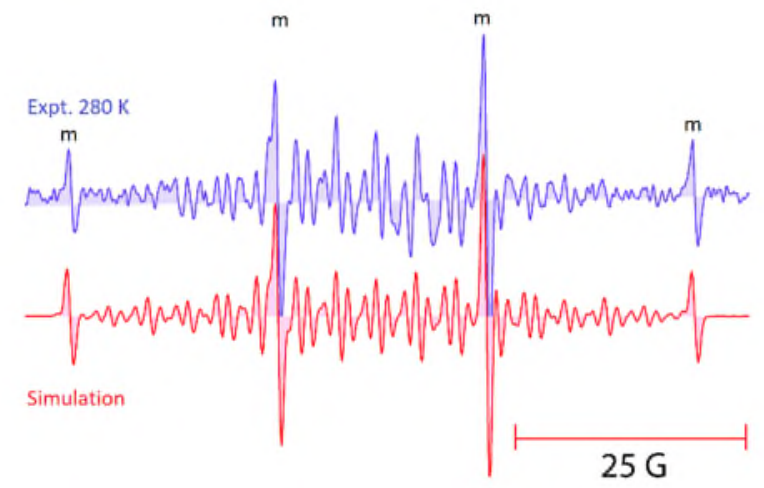

Figure 2. CW EPR Spectrum During UV Irradiation of 3a and DTBP in PhH.

Two radicals are clearly present in the resulting spectrum. The prominent quartet labeled " $\mathrm{m}$ " $[a(3 \mathrm{H})=22.6 \mathrm{G}]$ is due to methyl radicals derived from $\beta$-scission of the initial $t$-BuO radicals. The best fit of the spectrum $(\mathrm{R}=0.912)$ was obtained with Me• $(22 \%)$ plus a second radical $(78 \%)$ with the EPR parameters listed in Table 1.

Table 1. Experimental and Computed Isotropic EPR Parameters of Boriranyl Radicals. ${ }^{a}$

\begin{tabular}{llllllc}
\hline Radical & $\begin{array}{l}\text { T/K or } \\
\text { DFT }\end{array}$ & $g$-factor & $a\left({ }^{11} \mathrm{~B}\right)$ & $a(2 \mathrm{~N})$ & $a(2 \mathrm{H})$ & $a(2 \mathrm{H})$ \\
\hline $\mathbf{4 a}$ & 280 & 2.0029 & 8.64 & 4.23 & 11.88 & 1.33 \\
$\mathbf{4 a}$ & DFT1 $^{\mathrm{b}}$ & & 6.02 & 3.43 & 12.70 & -1.17 \\
$\mathbf{4 a}$ & DFT2 $^{\mathrm{c}}$ & & 11.81 & 4.08 & 11.81 & -1.23 \\
$\mathbf{4 b}^{\mathrm{d}}$ & 280 & 2.0028 & 8.5 & 4.0 & 11.4 & 1.4 \\
$\mathbf{4 b}$ & DFT3 $^{\mathrm{e}}$ & & 5.25 & 3.48 & 12.04 & -1.22 \\
$\mathbf{4 b}$ & DFT2 $^{\mathrm{c}}$ & & 11.21 & 3.90 & 11.25 & -1.21 \\
$\mathbf{6}^{\mathrm{f}}$ & 300 & 2.0028 & 7.3 & 4.0 & $11.4\left(\mathrm{H}^{\alpha}\right)$ & 1.0 \\
\hline
\end{tabular}

${ }^{\mathrm{a}}$ Hfs in Gauss. ${ }^{\mathrm{b}}$ DFT1 = UB3LYP/epr-ii//6-31+G(d,p). ${ }^{\mathrm{c}}$ DFT2 $=\mathrm{UB} 3 \mathrm{LYP} / 6-31+\mathrm{G}(\mathrm{d}, \mathrm{p})$. ${ }^{\mathrm{d}}$ Tentative data: see supporting information. ${ }^{\mathrm{e}}$ DFT3 = UB3LYP/epr-iii//6-31+G(d,p). ${ }^{\mathrm{f}}$ comparision radical 6 from $\mathrm{H}$-abstraction from (1,3-bis(2,6diisopropylphenyl)-1 $H$-imidazol-3-ium-2-yl)trihydroborate 5; see ref. 9.

\section{Scheme 2. Generation of Boriranyl Radicals ${ }^{a}$}<smiles>[R]n1cc[n+]([B])c1[BH-]1C(C)C1F</smiles><smiles>[131I-][131I-]</smiles>

3a, $\mathrm{R}=\operatorname{dipp}, \mathrm{E}=\mathrm{CO}_{2} \mathrm{Me}$

b, $\mathrm{R}=$ Mes, $\mathrm{E}=\mathrm{CO}_{2} \mathrm{Me}$<smiles>[B]c1n([Ge])cc[n+]1[O-]</smiles>

5<smiles>FC1B(c2n([Al])cc[n+]2[Bi])C1F</smiles>

$4 a, b$<smiles>[B]c1ccn(C2CCCCC2)c1[O-]</smiles>

6 a) Conditions: UV irradiation of solutions of DTBP and $\mathbf{3}$ in $\mathrm{PhH}$ at $280 \mathrm{~K}$.

The mesityl-NHC-borirane $\mathbf{3 b}$ was even less soluble in $\mathrm{PhH}$ than 3a, so the spectrum obtained from a sample of this, irradiated with DTBP, was extremely weak. However, a tentative analysis of this spectrum (see Supporting Information) yielded EPR parameters similar to those from reaction of $\mathbf{3 a}$ (see Table 1).

The EPR parameters obtained for the major species from each experiment are appropriate for boriranyl radicals $\mathbf{4 a}$ and $\mathbf{4 b}$ (Scheme 2). The EPR spectra from $\mathbf{4 a}, \mathbf{b}$ decayed instantly on shuttering the UV source so it follows both are transient, shortlived species. This contrasts with dipp-NHC-BH${ }_{2} \bullet$ radicals such as 6 that show significant persistency. ${ }^{9}$ The $a\left({ }^{11} \mathrm{~B}\right)$ hyperfine splitting (hfs) from $\mathbf{4 a}, \mathbf{b}$ and $\mathrm{hfs}$ from the $\mathrm{N}$ - and $\mathrm{H}$-atoms of the NHC rings are, however, quite similar in magnitude to that of dipp-NHC- $-\mathrm{BH}_{2} \bullet$ (see Table 1). This supports the identification of 4 and suggests that the configurations around the B-atoms of the two types of radical are similar planar $\pi$-type structures. Comparison with amine-boryl radicals such as $\mathrm{Me}_{3} \mathrm{~N}-\mathrm{BH}_{2} \bullet$ also supports this conclusion. Amine-boryl radicals are $\sigma$-type radicals, pyramidal at the B-atom, and they have much larger $a\left({ }^{11} \mathrm{~B}\right)$ hfs $[51.3$ $\mathrm{G}]^{12}$.

The DFT ${ }^{1 \square}$ computed structure of $\mathbf{4 a}$ and the associated SOMO are depicted in Figure 3 with hydrogen atoms omitted. The Batom forms part of a 3-member ring with all internal angles close to the equilateral $60^{\circ}$. The 3-member ring and the NHC-ring are nearly coplanar (dihedral $\angle \mathrm{CNBC}=10.8^{\circ}$ ) and the main SOMO density consists of a $\pi$-system spanning the B-atom and the NHCring. Because of the high spin density on boron, $\mathbf{4 a}$ is aptly described as a NHC-conjugated boriranyl radical (as opposed to a boron-substituted NHC-radical). The EPR hfs, computed with two DFT basis sets, are listed in Table 1 and agree reasonably well with the experimental values.
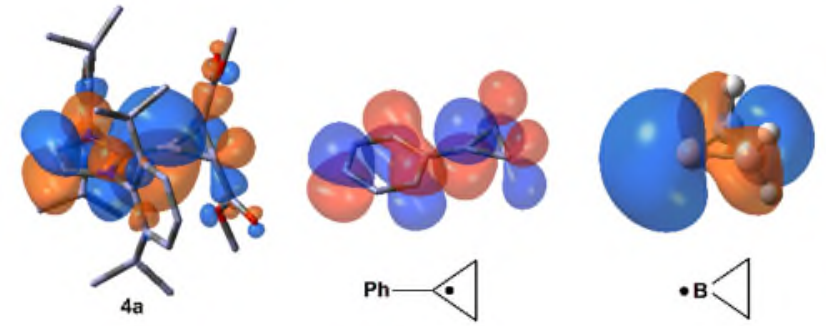

Figure 3. DFT Computed Structures and SOMOs of NHCBoriranyl 4a, 1-Phenylcyclopropyl \& Archetype Boriranyl Radicals

The NHC-borane radical 6 was shown to have a $\pi$-system similar to that of the benzyl radical. ${ }^{1} \square$ The analogous model for NHCborirane $\mathbf{4 a}$ is the 1-phenylcyclopropyl radical, the DFT computed structure and SOMO of which are also in Figure 3. 1Phenylcyclopropyl is a planar $\pi$-delocalized radical; the $\mathrm{Ph}$ ring suppresses the $\sigma$-character associated with the cyclopropyl radical itself. The $\pi$-system of $\mathbf{4 a}$ is very similar to that of the 1phenylcyclopropyl radical (Figure 3) with the NHC ring taking the place of the $\mathrm{Ph}$ ring. Possibly this is an indication that in 4a the NHC group suppresses $\sigma$-character that would be present in an unsubstituted boriranyl radical. The structure and SOMO of the archetype unsubstituted boriranyl radical $c-\mathrm{C}_{2} \mathrm{H}_{2} \mathrm{~B} \cdot$ were therefore also computed (Figure 3). ${ }^{\square} \quad$ These do indeed show a large $\sigma$ orbital associated with the B-atom. The huge computed EPR $a\left({ }^{11} \mathrm{~B}\right)$ for $c-\mathrm{C}_{2} \mathrm{H}_{2} \mathrm{~B}^{\bullet}$ of $218.9 \mathrm{G}$ was further indication of its $\sigma$ character.

The EPR experiments qualitatively show that H-atom abstraction from the NHC-boriranes $\mathbf{3 a}, \mathbf{b}$ by $t$-butoxyl radicals is considerably slower than from NHC-borane 6. To quantify this step, 
competition experiments were carried out with 2-methoxy-2methylpropane $\left(t-\mathrm{BuOCH}_{3}\right)$; a substrate expected to be of comparable reactivity to $\mathbf{3 a}$. EPR spectra containing signals from radical $4 \mathbf{a}$ and the $t-\mathrm{BuOCH}_{2} \bullet$ radical were obtained. From the EPR spectra of solutions containing known concentrations of $\mathbf{3 a}$ and $t$ $\mathrm{BuOCH}_{3}$ the ratio of the two radicals was determined and the results were averaged (details in the Supporting Information). The ratio $k \mathrm{H}(3 \mathbf{a}) / k_{\mathrm{H}}\left(t-\mathrm{BuOCH}_{3}\right)=2.24$ at $280 \mathrm{~K}$ was then obtained by the method described prevously. ${ }^{9}$ Arrhenius parameters for $k_{\mathrm{H}}(t$ $\left.\mathrm{BuOCH}_{3}\right)$ were published by Roberts and co-workers, ${ }^{1} \square$ and hence the rate constant for $\mathrm{H}$-atom abstraction from borirane 3a by $t$ - $\mathrm{BuO} \bullet$ radicals was found to be:

$$
k_{\mathrm{H}}(3 \mathbf{a})=1.3 \times 10^{6} \mathrm{M}^{-1} \mathrm{~s}^{-1} \text { at } 280 \mathrm{~K}
$$

Comparison of this with the two independent determinations of the rate constant for $\mathrm{H}$-atom abstraction from $\mathrm{NHC}$-borane $\mathbf{5}$, i.e. $k_{\mathrm{H}}(\mathbf{5})=9.5 \times 10^{7}$ and $\leq 1.4 \times 10^{8} \mathrm{M}^{-1} \mathrm{~s}^{-1}$ at $293 \mathrm{~K},{ }^{9,1} \square$ shows that abstraction of the (B)-H atom from the 3 -membered ring is 2 orders of magnitude slower than from $(\mathrm{B}) \mathrm{H}_{3}$. The $k_{\mathrm{H}}$ for $\mathrm{H}$-atom abstraction from secondary $\mathrm{CH}_{2}$ in an $n$-alkane by $t$-BuO• is $\sim 1 \times$ $10^{6} \mathrm{M}^{-1} \mathrm{~s}^{-1} ; \square \mathrm{H}$-abstraction from cyclopropane is known to be slower than this. It follows that the borirane (B) $-\mathrm{H}$ is somewhat more reactive to $\mathrm{H}$-abstraction than is cyclopropyl- $\mathrm{H}$.

An estimate of the bond dissociation energy (BDE) of $\mathrm{B}-\mathrm{H}$ in 3a can be obtained by applying an Evans-Polanyi (E-P) type relationship. A plot of the logarithms of published rate constants for $\mathrm{H}$-abstraction from various substrates ${ }^{19}$ vs. the corresponding $\mathrm{X}-\mathrm{H}$ BDEs produces the following E-P relationship (see Supporting Information):

$$
\mathrm{BDE}(\mathrm{X}-\mathrm{H}) / \mathrm{kcal} \mathrm{mol}^{-1}=-3.373 \times \log \left(k_{\mathrm{H}}\right)+116.04
$$

Use of this equation with $k_{\mathrm{H}}(\mathbf{3 a})$ furnished an estimate of 95.5 $\mathrm{kcal} \mathrm{mol}^{-1}$ for the BDE of the B-H bond in the NHC-substituted borirane 3a. Use of this E-P relationship with $k_{\mathrm{H}}$ for NHC-borane 6 (see above) afforded a B-H BDE of $88.6 \mathrm{kcal} \mathrm{mol}^{-1}$ in close agreement with the previous estimate ${ }^{9}$ of $88 \mathrm{kcal} \mathrm{mol}^{-1}$. This adds confidence to the validity of the estimates.

The computed BDE of the $\mathrm{B}-\mathrm{H}$ bond in $\mathrm{Me}_{2} \mathrm{~B}-\mathrm{H}$ is $104-105$ kcal mol ${ }^{-1}$. $^{\square}$ Comparing this to the BDE of $\square$, NHC substitution reduces $\mathrm{B}-\mathrm{H}$ BDEs by about $16 \mathrm{kcal} \mathrm{mol}^{-1}$. Likewise, the NHC substituent in 3a probably reduces its $\mathrm{B}-\mathrm{H}$ BDE by a comparable amount. If so, then the $\mathrm{B}-\mathrm{H}$ BDE of unsubstituted borirane itself $\left(\mathrm{C}_{2} \mathrm{H}_{5} \mathrm{~B}\right)$ would be about $110 \mathrm{kcal} \mathrm{mol}^{-1}$. Thus, B-H bonds in 3member rings would be $\sim 5 \mathrm{kcal} \mathrm{mol}^{-1}$ stronger than in straight chain boranes. This makes good sense because the $\mathrm{C}-\mathrm{H}$ BDE of cyclopropane $\left(106.3 \mathrm{kcal} \mathrm{mol}^{-1}\right)$ is also $\sim 5 \mathrm{kcal} \mathrm{mol}^{-1}$ stronger than that of straight chain hydrocarbons.

$\mathrm{H}$-Atoms were indeed selectively abstracted by $t$-butoxyl radicals from the recently prepared NHC-ligated boriranes 3. This enabled NHC-boriranyl radicals to be experimentally observed and spectroscopically characterized for the first time. This revealed them to be planar $\pi$-type species resembling 1phenylcyclopropyl radicals. From competition experiments, abstraction of (B)-H from NHC-boriranes turned out to be about 2 orders of magnitude slower that (B)-H abstraction from NHCboranes. Thus the $\mathrm{B}-\mathrm{H}$ bond in a 3-member ring resembled the $\mathrm{C}-\mathrm{H}$ bond in being stronger than in open chain analogs.

\section{ASSOCIATED CONTENT}

\section{Supporting Information}

Preparation of boriranes, EPR spectra, details of relative rate determination, Evans-Polanyi plot, DFT optimum structures. The Supporting Information is available free of charge on the ACS Publications website.

\section{AUTHOR INFORMATION}

\section{Corresponding Authors}

*jcw@st-andrews.ac.uk; * curran@pitt.edu

\section{ORCID}

John C. Walton: 0000-0003-2746-6276

Dennis P. Curran: 0000-0001-9644-7728

\section{ACKNOWLEDGMENTS}

JCW thanks EaStCHEM for financial support. TRM and DPC thank the US National Science Foundation for grant CHE1660927.

\section{REFERENCES}

(1) (a) Bissinger, P.; Braunschweig, H.; Kraft, K.; Kupfer, T. Angew. Chem. Int. Ed. 2011, 50, 4704-4707. (b) Braunschweig, H.; Claes, C.; Damme, A.; Deissenberger, A.; Dewhurst, R. D.; Hörl, C.; Kramer, T. Chem. Commun. 2015, 51, 1627-1630.

(2) Rao, Y.-L.; Chen, L. D.; Mosey, N. J.; Wang, S. J. Am. Chem. Soc. 2012, 134, 11026-11034.

(3) McFadden, T. R.; Fang, C.; Geib, S. J.; Merling, E.; Liu, P.; Curran, D. P. J. Am. Chem. Soc. 2017, 139, 1726-1729.

(4) Fessenden, R. W.; Schuler, R. H. J. Chem. Phys. 1963, 39, 2147-2195. (5) (a) Hudson, C. E.; Bauld, N. L. J. Am. Chem. Soc. 1972, 94, 11581163; (b) Kawamura, T.; Tsumura, M.; Yokomichi, Y.; Yonezawa, T. J. Am. Chem. Soc. 1977, 99, 8251-8256; (c) Deycard, S.; Hughes, L.; Lusztyk, J.; Ingold, K. U. J. Am. Chem. Soc. 1987, 109, 4954-4960.

(6) Hioe, J.; Zipse, H. Radical Stability - Thermochemical Aspects. In Encyclopedia of Radicals in Chemistry, Biology and Materials; Chatgilialoglu, C.; Studer, A., eds.; Wiley: 2012, vol. 1, pp 449-475.

(7) (a) Danen, W. C.; Kensler, T. T. Tetrahedron Lett. 1971, 2247-2250; (b) Purcell, K. F.; Danen, W. C. J. Am. Chem. Soc. 1972, 94, 7613-7619.

(8) (a) Hannachi, Y.; Hassanzadeh, P.; Andrews, L. Chem. Phys. Lett. 1996, 250, 421-427; (b) Andrews, L.; Lanzisera, D. V.; Hassanzadeh, P.; Hannachi, Y. J. Phys. Chem. A, 1998, 102, 3259-3267.

(9) (a) Ueng, S.-H.; Solovyev, A.; Yuan, X.; Geib, S. J.; Fensterbank, L.; Lacôte, E.; Malacria, M.; Newcomb, M.; Walton. J. C.; Curran, D. P. J. Am. Chem. Soc. 2009, 131, 11256-11262; (b) Walton. J. C.; Makhlouf Brahmi, M.; Fensterbank, L.; Lacôte, E.; Malacria, M.; Chu, Q.; Ueng, S.H.; Solovyev, A.; Curran, D. P. J. Am. Chem. Soc. 2010, 132, 2350-2358; (c) Walton, J. C.; Makhlouf Brahmi, M.; Monot, J.; Fensterbank, L.; Malacria, M.; Curran, D. P.; Lacôte, E. J. Am. Chem. Soc. 2011, 133, 10312-10321.

(10) Luo, Y.-R. Handbook of Bond Dissociation Energies in Organic Compounds, CRC Press, Boca Raton, 2003.

(11) Minor amounts of ${ }^{\circ} \mathrm{CMe}_{2} \mathrm{CH}_{2} \mathrm{Ph}$ from 1,2-phenyl migration were detected at higher temperatures.

(12) (a) Kirwan, J. N.; Roberts, B. P. J. Chem. Soc., Perkin Trans. 2 1989, 539-550; (b) Paul, V.; Roberts, B. P.; Robinson, C. A. S. J. Chem. Res. (S) 1988, 264-265.

(13) Gaussian 09, Revision D.01, Frisch, M. J.; Trucks, G. W.; Schlegel, H. B.; Scuseria, G. E.; Robb, M. A.; Cheeseman, J. R.; Scalmani, G.; Barone, V.; Petersson, G. A.; Nakatsuji, H.; Li, X.; Caricato, M.; Marenich, A.; Bloino, J.; Janesko, B. G.; Gomperts, R.; Mennucci, B.; Hratchian, H. P.; Ortiz, J. V.; Izmaylov, A. F.; Sonnenberg, J. L.; Williams-Young, D.; Ding, F.; Lipparini, F.; Egidi, F.; Goings, J.; Peng, B.; Petrone, A.; Henderson, T.; Ranasinghe, D.; Zakrzewski, V. G.; Gao, J.; Rega, N.; Zheng, G.; Liang, W.; Hada, M.; Ehara, M.; Toyota, K.; Fukuda, R.; Hasegawa, J.; Ishida, M.; Nakajima, T.; Honda, Y.; Kitao, O.; Nakai, H.; Vreven, T.; Throssell, K.; Montgomery, J. A. Jr.; Peralta, J. E.; Ogliaro, F.; Bearpark, M.; Heyd, J. J.; Brothers, E.; Kudin, K. N.; Staroverov, V. N.; Keith, T.; Kobayashi, R.; Normand, J.; Raghavachari, K.; Rendell, A.; Burant, J. C.; Iyengar, S. S.; Tomasi, J.; Cossi, M.; Millam, J. M.; Klene, M.; Adamo, C.; Cammi, R.; Ochterski, J. W.; Martin, R. L.; Morokuma, K.; Farkas, O.; Foresman, J. B.; Fox, D. J. Gaussian, Inc., Wallingford CT, 2016.

(14) Walton, J. C. Angew. Chem. Int. Ed. 2009, 48, 1726-1728.

(15) DFT with CAM-B3LYP/6-311+G(2d,p) method.

(16) Baban, J. A.; Goddard, J. P.; Roberts, B. P. J. Chem. Soc. Perkin Trans. 2, 1986, 1269-1274. 
(17) Tehfe, M.-A.; Monot, J.; Malacria, M.; Fensterbank, L.; Fouassier, J.P.; Curran, D. P.; Lacôte, E.; Lalevée, J. ACS Macro Lett. 2012, 1, $92-95$.

(18) Wong, S. K. Int. J. Chem. Kinet. 1981, 13, 433-444.

(19) Howard, J. A.; Scaiano, J. C. in Landolt-Börnstein, Radical Reaction Rates in Liquids, Vol. 13d, Oxyl-, Peroxyl- and Related Radicals. ed. Fischer, H. Springer-Verlag, Berlin, 1984.

(20) Rablen, P. R.; Hartwig, J. F. J. Am. Chem. Soc. 1996, 118, 46484653.
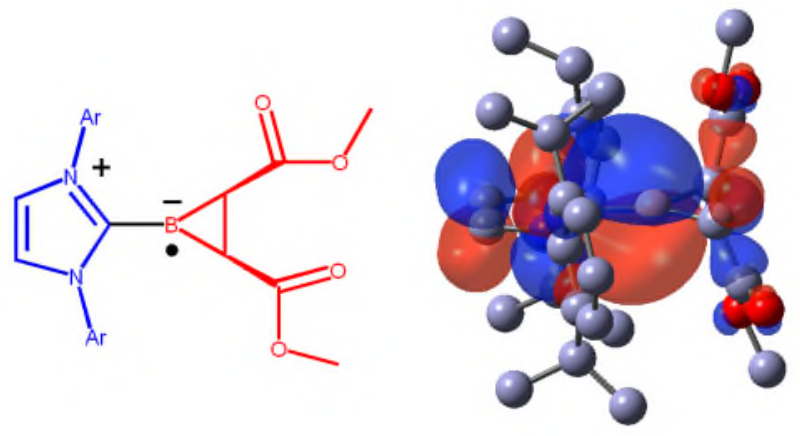